\title{
Correlation between air temperature and electricity demand by linear regression and wavelet coherence approach: UK, Slovakia and Bosnia and Herzegovina case study
}

\author{
Samir Avdakovic ${ }^{1}$, Alma Ademovic ${ }^{1}$, Amir Nuhanovic ${ }^{2}$ \\ ${ }^{1}$ EPC Elektroprivreda B\&H D.D. Sarajevo, Department of Strategic Development \\ Vilsonovo setaliste 15, 71000 Sarajevo, Bosnia and Herzegovina \\ tel.: +38733751872, fax: +38733751056 \\ e-mail: \{s.avdakovic/al.ademovic\}@elektroprivreda.ba \\ ${ }^{2}$ University of Tuzla, Faculty of Electrical Engineering, Department of Power Systems Analysis \\ Franjevacka 2, 75000 Tuzla, Bosnia and Herzegovina \\ e-mail: amir.nuhanovic@untz.ba
}

(Received: 04.12.2012, revised: 03.03.2013)

\begin{abstract}
In this paper, the results of correlations between air temperature and electricity demand by linear regression and Wavelet Coherence (WTC) approach for three different European countries are presented. The results show a very close relationship between air temperature and electricity demand for the selected power systems, however, the WTC approach presents interesting dynamics of correlations between air temperature and electricity demand at different time-frequency space and provide useful information for a more complete understanding of the related consumption.
\end{abstract}

Key words: power system, electricity demand, air temperature, linear regression, wavelet coherence

\section{Introduction}

The electric power system is a very complex system. It is composed of a large number of different elements such as generators, lines, transformers, etc., but it also has a lot of different consumption categories such as household, industrial, transportation, and others. Short, medium or long-term planning requires thorough understanding of consumption characteristics which are defined by their load curves. The load curves represent characteristics of the power system's load variability as a function of time, and their analysis can be performed for some customer groups, some geographic areas or the power system as a whole, where it is very important to identify the main factors affecting the consumption of electricity, such as growth and structure of Gross Domestic Product (GDP), demographic change, housing standard, the 
mobility of the population, climate change, change in energy efficiency, habits and customs, etc. Air temperature is one of the factors that could significantly affect the consumption of electricity, which is evident in its seasonal variations. Several different approaches to determining the influence of air temperature on the electricity consumption are presented in Refs. [1-7]. Also, variations of air temperature are an important factor in the forecast of electricity consumption, especially the short-term and mid-term, as reported by References [8-10]. On the other hand, in the past few years, Wavelet Transform (WT) has found its application in almost all fields of science. A wavelet $\varphi(t)$ is a small wave with a finite duration (compact support) or finite energy. It is called a wave because of its oscillatory nature, and it is small because of the final domain in which it is different from zero (compact support) [11]. Due to the time-frequency property, the WT has the advantage over other techniques for signal processing and analysis. Also, the WT has found application in the analysis of load curves or analysis of electricity demand with a focus on load forecasting [12-14], clustering data [15] or power balancing [16].

In this paper, a linear regression and Wavelet Coherence (WTC) approach have been conducted to explore and illustrate the impact of air temperature on electricity demand for three different European countries (United Kingdom (UK), Slovakia (SK) and Bosnia and Herzegovina $(\mathrm{B} \& \mathrm{H}))$. A linear regression is a commonly used mathematical method in different scientific areas. A detailed mathematical elaboration can be found in many books and papers, while its practical application in the field treated by this paper can be found in $[1,4$, 17-18]. A linear regression is used in this study to analyse temperature sensitivities of selected power systems electricity demand, while WTC is used to analyse/explore co-movement between time series of air temperature and electricity demand at different time-frequency space. This paper is a continuation to our research presented in [19-20], where the Morlet wavelet function is used to perform time-frequency analysis of a power system's load variance [19], which allows the identification of characteristic periods of electricity consumption over time and a better understanding of the dynamic behaviour of the related consumption [19]. The study presented in [20] also used a linear regression and WTC approach to explore interrelationship between GDP, seasonal air temperature variations and quarterly electricity demand on a 1971-2011 time series for the UK. The results of the wavelet correlation at different time-scale space for the UK indicate that significant correlation is to be found on a long-term basis for GDP ( 8 years) and at an annual basis for seasonal air temperature changes [20].

The methodology (WTC) used in this paper has been proposed in [21-22], where the Morlet WT analysis has been applied to estimate the spectral characteristics of a data time series, showing the fluctuations of the periodic components as a function of time and allows to explore the relationships between two time series. This methodology has been used in many areas of science [23-29] and the software tools used in this paper are available in [30] provided by authors of [22].

This paper is organized as follows: methodology and data used in this paper are presented in Section 2. Data analysis, results and discussions are presented in Section 3, while Section 4 provides conclusions. 


\section{Data and applied methodological approach}

The word 'regression' in mathematical terms was coined in 1855, and it is a research results of the English scientist Francis Galton. Regression analysis evaluates potential relationship between two variables by means of a regression line, and a detailed mathematical description of this approach is available in a number of books and papers. For basic analyisis and relative comparisson it has been considered a relevant tool in this work as well.

The second methodological approach, proposed in [21-22] and used in this paper as well, originates from a relatively young mathematical discipline, applied in different scientific areas. Continuous WT (CWT) of a time series $x_{n},(n=1,2,3, \ldots, N)$ with a wavelet function $\varphi(t)$ and equal time intervals $\delta_{t}$ is defined as [28]:

$$
W_{m}(s)=\frac{\delta_{t}}{\sqrt{s}} \sum_{n=0}^{N-1} x_{n} \varphi *\left[\frac{(n-m) \delta_{t}}{s}\right], m=0,1, \ldots, N-1,
$$

where: $*$ - denotes the conjugate complex value, $N$ - are the the number of points in the evaluated time series and $\varphi(t)$ - is the wavelet function at scale $s$, translated in time by $m$.

Equation (1) describes the convolution of the time series with a scaled and translated version of the wavelet function. The local wavelet power spectrum $\left|W_{n}(s)\right|^{2}$ is obtained as the squared absolute value of the wavelet coefficients (or squared amplitude), while the Cross-WT (XWT) of two time series, $x_{n}$ and $y_{n}$, is defined as $W_{n}^{x y}=W_{n}^{x} W_{n}^{y *}$, where $W_{n}^{x}$ and $W_{n}^{y}$ are the WT of the $x$ and $y$ time series, respectively. The value $\left|W_{n}^{x y}\right|$ represents thereby the crosswavelet power. At each defined scale, the cross-wavelet power of two time series suggests the local covariance between the analysed data sets and provides an insight into their power similarity. This ability provides excellent features to determine the relationship between the two time series and their common power in the time-frequency domain [22-28].

The WTC can be explained as a measure of the intensity of the covariance of the two time series in the time-frequency space or the local correlation between the time series in the timefrequency space. The WTC is defined as the squared absolute value of the smoothed cross wavelet spectra normalized by the product of the smoothed individual wavelet power spectra of each series [21-29]:

$$
R_{n}^{2}(s)=\frac{\left|S\left(s^{-1} W_{n}^{x y}(s)\right)\right|^{2}}{S\left(s^{-1} W_{n}^{x}(s)\right)^{2} S\left(s^{-1} W_{n}^{y}(s)\right)^{2}},
$$

where $S$ is a smoothing operator. The squared wavelet coherence coefficient is in the range $0 \leq R_{n}^{2}(s) \leq 1$ and values close to zero indicate weak correlation, while values close to one provide evidence of strong correlation [21-29].

The phase-difference between the two time series is defined as an argument of the smoothed real and imaginary fragments of the cross-spectrum [29] and it provides information on the delays of the oscillations between the two time series. 
To illustrate the impact of air temperature on electricity demand, we have selected three different European countries - UK, Slovakia and B\&H, for further analysis. The data on daily electricity consumption and daily average temperatures in the UK for the period 2005-2011 are presented in Figure 1 and have been taken over from [31-32], respectively. In general, the UK represents one of the economically most developed countries of the world. However, in the last few years a reduction in electricity consumption has been identified (Tab. 1). For the period 2005-2011, average daily temperatures in this region were found to be ranging from $7.0^{\circ} \mathrm{C}$ up to $24.5^{\circ} \mathrm{C}$ (Tab. 1). Time series in Figure 1 are represented by 2.556 sample points.

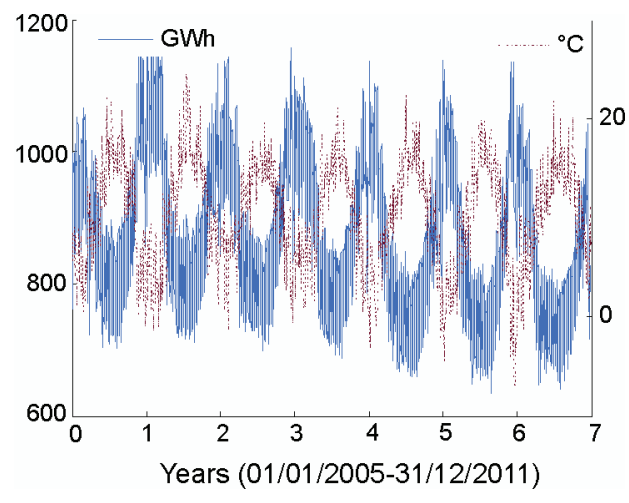

Fig. 1. UK - daily values of electricity demand and mean air temperature for 2005-2011

Daily electricity consumption and daily average air temperature for Slovakia for the period 1997-1998 are presented in Figure 2 and have been taken over from [33]. Slovakia is a central European country with a stable economy and in the period from 1997-1998 it has experienced an increase in electricity consumption. Average daily temperatures were found to be ranging from $-14.2^{\circ} \mathrm{C}$ up to $26.5^{\circ} \mathrm{C}$ (Tab. 1). Time series in Figure 2 are represented by 730 sample points.

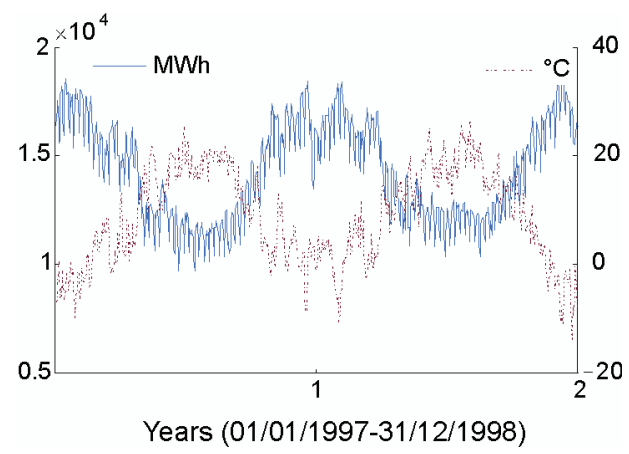

Fig. 2. Slovakia - daily values of electricity demand and mean air temperature for 1997-1998

B\&H hourly values of air temperature and electricity demand for 2008-2010 are presented in Figure 3. The data on electricity demand (power system loads) have been provided by EPC Elektroprivreda B\&H-Sarajevo and represent a consumption of about 700.000 costumers. 
Hourly air temperature oscillations presented in Figure $3 b$ have been taken over from the Federal Hydrometeorological Institute of $\mathrm{B} \& \mathrm{H}$, where measurements are given for the area of the city of Sarajevo only. It can be observed that, compared to the other two countries, the temperature here oscillates in quite a vast range from $-15.6{ }^{\circ} \mathrm{C}$ up to $36.7^{\circ} \mathrm{C}$ (Tab. 1). Time series in Figure $3 \mathrm{~b}$ are represented by 26280 sample points. Daily electricity consumption and average daily temperatures presented in Figure $3 a$ are calculated from the data in Figure $3 b$.

For the three selected power systems, from a first look an obvious relationship between air temperature and power system electricity consumption can be observed. Rise of temperature in the summer months significantly reduces electricity consumption, while on the other hand, temperature fall in winter causes the opposite (Figs. 1-3). Basic information on yearly electricity demand and air temperature depicted in Figures 1-3 are presented in Table 1.

\section{Results and discussions}

This section contains the main results and findings of the analyses performed for the selected data sets, using the previously described two methodological approaches for time series comparison. In the first part a temperature sensitivity analysis using a linear regression approach is presented, whereas in the second part a time frequency analysis using WTC is depicted and explained. Discussion is given along the relevant paragraphs.

a)

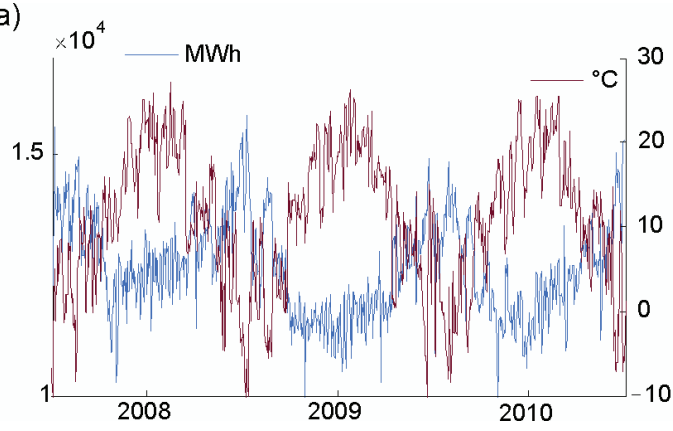

b)

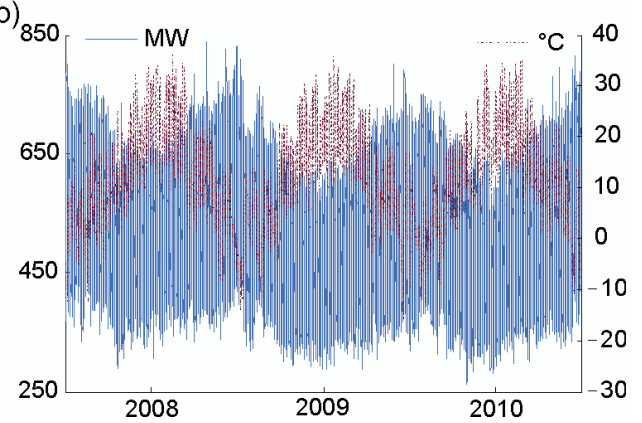

Fig. 3. B\&H - a) daily values of electricity demand and air temperature for 2008-2010, b) hourly values of electricity demand and air temperature for 2008-2010

\subsection{Temperature sensitivity analysis using linear regression}

Mathematically, the interdependence between air temperature and electricity demand using linear regression is given as: $y=a x+b$, where: $y$ represents electricity demand, $x$ denotes air temperature and $a$ and $b$ are the respective regression coefficients. The Pearson correlation coefficient is defined as $r=\sigma_{x y}^{2} / \sigma_{x} \sigma_{y}$, where $\sigma_{x y}^{2}$ represents the covariance of the $x$ and $y$ time series, while $\sigma_{x}$ and $\sigma_{y}$ are the standard deviations of $x$ and $y$, respectively. $r$-square $\left(r^{2}\right)$ is a coefficient used for evaluation of the representativeness of the regression model, which is based on analysis of the respective variance. It is defined as the ratio of the sum of 
squared deviations interpreted by regression and the total sum of squares of deviations. The coefficient ranges from 0 to 1 and the regression model is more representative if the indicator is closer to the upper value.

Table 1. Basic information of yearly electricity demand and air temperature from Figures 1-3

\begin{tabular}{c|c|c|c|c|c|c|c|c|c}
\hline \multirow{2}{*}{} & \multicolumn{3}{|c|}{ UK } & \multicolumn{3}{c|}{ Slovakia } & \multicolumn{3}{c}{ B\&H } \\
\cline { 2 - 10 } & & avg. daily ${ }^{\circ} \mathrm{C}$ & & \multicolumn{2}{c|}{ avg. daily ${ }^{\circ} \mathrm{C}$} & & \multicolumn{2}{c}{ avg. daily/hourly ${ }^{\circ} \mathrm{C}$} \\
\hline Year & GWh & $\min$ & $\max$ & GWh & $\min$ & $\max$ & GWh & min & $\max$ \\
\hline 1997 & - & - & - & 5198 & -10.0 & 25.3 & - & - & - \\
\hline 1998 & - & - & - & 5250 & -14.2 & 26.5 & - & - & - \\
\hline- & - & - & - & - & - & - & - & - & - \\
\hline 2005 & 332974.2 & -1.0 & 22.1 & - & - & - & - & - & - \\
\hline 2006 & 340721.8 & -1.4 & 24.5 & - & - & - & - & - & - \\
\hline 2007 & 333411.5 & -1.5 & 19.7 & - & - & - & - & - & - \\
\hline 2008 & 331599.2 & -0.3 & 21.1 & - & - & - & 4797.5 & $-10.47 /-12.8$ & $27.11 / 36.3$ \\
\hline 2009 & 314271.2 & -3.0 & 22.5 & - & - & - & 4499.3 & $-11.05 /-15.6$ & $26.24 / 35.8$ \\
\hline 2010 & 319700.5 & -7.0 & 19.9 & - & - & - & 4583.6 & $-8.43 /-12.8$ & $26.30 / 36.7$ \\
\hline 2011 & 307033.7 & -1.4 & 22.0 & - & - & - & - & - & - \\
\hline
\end{tabular}

Correlations between electricity demand and air temperature for the time series in Figures 1-3a, applying the linear regression approach, are presented in Figure 4, where for relative comparison of the electricity demand, UK data are presented in 100 [MWh] units. The variables of air temperature and electricity demand in all three cases are normally distributed, and the values of calculated coefficients $\left(r\right.$ and $\left.r^{2}\right)$ are: UK: $r=-0.7084$ and $r^{2}=0.502$; Slovakia: $r=-0.8833$ and $r^{2}=0.780$; B\&H: $r=-0.6438$ and $r^{2}=0.414$.

It can be observed that electricity consumption in Slovakia has the lowest dispersion, hence the correlation coefficient for Slovakia is the highest. Due to the volume of data, all correlations are significant to a very high degree. The reason for the relatively lower correlation for $\mathrm{B} \& \mathrm{H}$ is the fact that the electricity consumption begins to grow when average daily temperatures exceed $20^{\circ} \mathrm{C}$ (Fig. 4). Also, results presented in Figure 4 which relate to the daily consumption and air temperature changes for UK, Slovakia and B\&H, indicate that for these systems there is a relatively strong linear dependency between air temperature and electricity demand.

The results of the regression analysis show that all regressions and coefficients are significant, while the coefficient of determination is the highest for the model of Slovakia. This means that $78 \%$ of the variability of electricity consumption in Slovakia can be explained by the average daily air temperature variation. For the UK model this value goes down to $50 \%$, while for B\&H it accounts only for $41 \%$ of the time series. In other words, for the UK time series plotted in Figure 4 as the daily electricity demand against daily mean air temperature, the fitted curve shows temperature sensitivity of the electricity demand of about $15.500 \mathrm{GWh} /{ }^{\circ} \mathrm{C}$ (Tab. 3), with a relatively high coefficient of determination approximately 
$50 \%$. Also, a strong linear dependency of air temperature and electricity demand is observed for Slovakia and $\mathrm{B} \& \mathrm{H}$, where air temperature sensitivity of electricity demand for Slovakia is at about $226 \mathrm{MWh} /{ }^{\circ} \mathrm{C}$, whereas for the $\mathrm{B} \& \mathrm{H}$ system it is at about $78 \mathrm{MWh} /{ }^{\circ} \mathrm{C}$.

Fig. 4. Correlations between electricity demand and air temperature for selected power systems

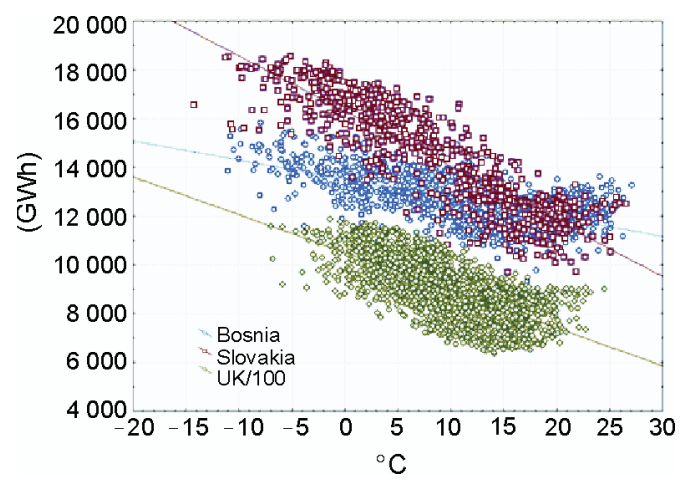

However, regression statistics for hourly B\&H electricity demand have a very low coefficient of determination, indicating that the linear regression approach is not suitable for analyses of the hourly time series from Figure $3 \mathrm{~b}$. Also, it is expected that the electricity demand depending on air temperature is not the same for all months or all seasons of the year. A detailed regression analysis on the monthly scale of a daily consumption and air temperature changes is also accompanied by very low values of coefficient of determination $\left(r^{2}\right)$, which indicates the need for other approaches.

\subsection{Wavelet coherence between air temperature and electricity demand}

To explore and illustrate the co-movement between air temperature and electricity demand at different time-frequency (period) space, in this section the WTC approach is applied. The WTC indicates to the regions in time-frequency space where the two time series co-vary and the colour code in Figures 5-7 indicates different WTC ranges, ranging from blue (low power) to red (high power), adding to the significance of the regions $[19,25]$. The phase difference between the two time series is defined by arrows [21]. The orientation of the arrows indicates the level and type of correlation, as well as the relative bond between the studied phenomena, in terms of their time shift [27]. The WTC of UK air temperature and electricity demand for the period 2005-2011, is presented in Figure 5. Evidently, this approach provides some important information about the dynamic behaviour of the time series under study and the WTC graph reveals the co-movement of the two time series, offering an interesting insight into the studied phenomenon. The first characteristic period can be identified in the period between 16 and 32 days and several intervals during the observed time horizon. Also, air temperature and electricity demand in the UK in this period and identified intervals are out of phase. This is especially evident in the days around New Years 2007-2008, 2008-2009, 2009-2010 and 2010-2011.

In the period between 64 and 128 days, significant correlations between time series are identified for the interval 2007 and at the end of 2009 and early 2010, also with out of phase, while for the period about 256 days, air temperature and electricity demand co-move out of 
phase during all observed time interval. This indicates the high seasonal dependence between UK electricity demand and air temperature variations.

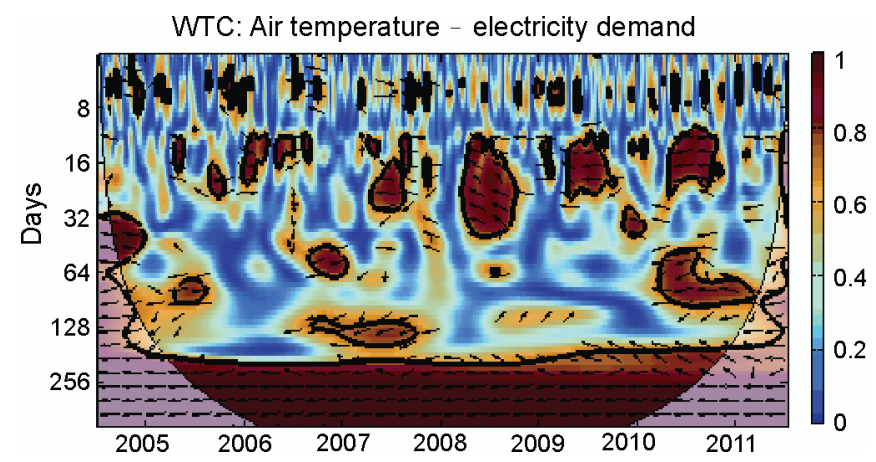

Fig. 5. WTC of daily values of air temperature and electricity demand for UK in the period of 2005-2011

Using the same approach, the WTC of air temperature and electricity demand time series for Slovakia is obtained, for the period of 1997-1998, as presented in Figure 6. In the 16-64 day bands and the first half of 1997 an interesting area is identified, where the time series are completely out of phase. Also, significant correlation between electricity consumption and air temperature in this power system is evident during the last months of 1997 and 8-32 day bands. Out of phase co-movement are identified in the first half of 1998 and 16-32 day bands, while for the second half of 1998 no conclusion could be drawn.

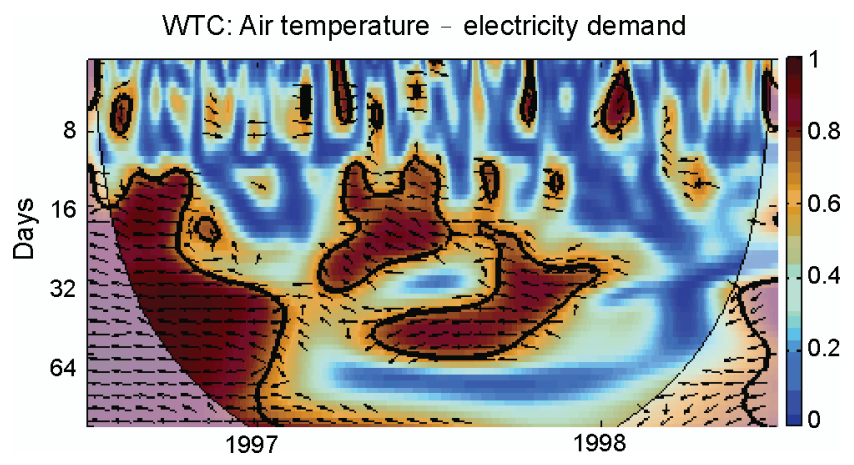

Fig. 6. WTC of air temperature and electricity demand for Slovakia in the period of 1997-1998

A more detailed analysis can be performed with hourly values of electricity consumption and air temperature, as it is the case with the time series in Figure $3 \mathrm{~b}$. The WTC of the hourly air temperature and electricity demand values of B\&H for the period of 2008-2010 is presented in Figure 7. In the 24 hour bands (one day) and all observed time horizon, strong interdependence and co-movement between air temperature and electricity demand is evident, with a strong phase relationship. This is very interesting as it indicates positive trends in electricity consumption with increase of air temperature in the 24 hour bands. 

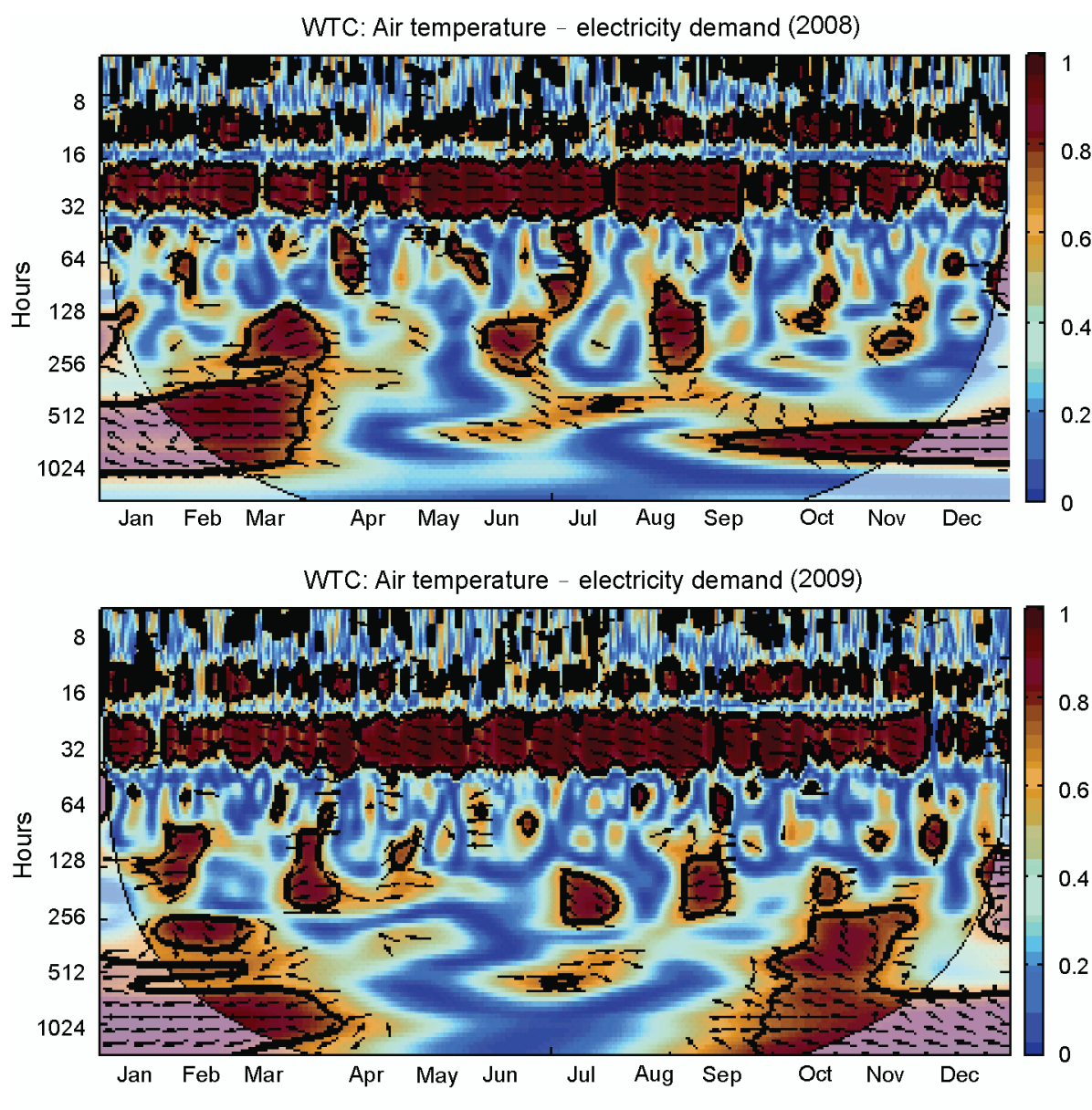

WTC: Air temperature - electricity demand (2010)

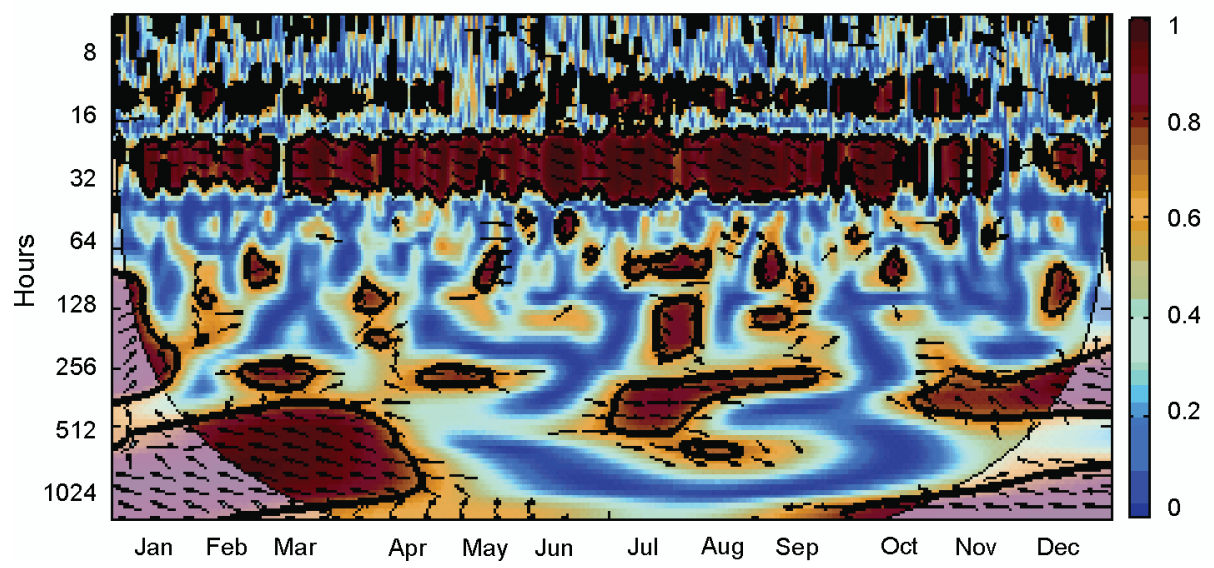

Fig. 7. WTC of the hourly values of air temperature and electricity demand for B\&H in the period of 2008-2010 
For all three years, strong interdependence between air temperature and electricity demand with an anti-phase relationship is identified in the period of 512-1024 hour bands and seasons of autumn and winter. This is especially pronounced in the winter season, which can be explained by the tendency of electricity demand to increase as a result of temperature fall on a seasonal basis.

However, during the period of 128-512 hour bands, part of spring and summer are marked by arrows to the right, which points to a strong seasonal interdependence of the two time series. In other words, for the $\mathrm{B} \& \mathrm{H}$ power system and in the certain days of spring and summer, the temperature rise will cause an increase in electricity consumption. Such findings are not very likely to be drawn from simple plots as in Figure 3, which shows that this approach is quite effective for obtaining very important information that may contribute to a better understanding of own electricity consumption and better power system planning.

\section{Conclusions}

In this paper, a linear regression and WTC approach is used to explore and illustrate the interdependence of two time series - air temperature and electricity demand, using data of three different European countries. For all of the selected data sets used in this study, a close correlation between air temperature and electricity consumption is identified, with particular emphasis on the seasonal temperature variations which have a significant impact on electricity consumption. Results of the regression analysis for all of the three analysed power systems show a relatively strong linear dependency between air temperature and electricity demand. It is shown that for the power system of Slovakia, the coefficient of determination is the highest, where $78 \%$ of the variability of electricity consumption can be explained by the average daily air temperature variations, while this number for the UK and $\mathrm{B} \& \mathrm{H}$ goes down to $50 \%$ and $41 \%$, respectively. The fitted lines of daily electricity demand against daily mean air temperature, show temperature sensitivity of the electricity demand. For the UK these values are at about $15.500 \mathrm{GWh} /{ }^{\circ} \mathrm{C}$, for Slovakia at $226 \mathrm{MWh} /{ }^{\circ} \mathrm{C}$, whereas for the $\mathrm{B} \& \mathrm{H}$ power system the values are at some $78 \mathrm{MWh} /{ }^{\circ} \mathrm{C}$. However, regression statistics for hourly $\mathrm{B} \& \mathrm{H}$ time series and daily time series on the monthly time scale have been characterised by a very low coefficient of determination, which suggests potential need to explore other alternative approaches.

The WTC approach used in this paper enables a time-frequency analysis of the time series, helping identify time frames in which significant correlation between air temperature and electricity demand can be expected, which has been presented in the three selected test systems. Also, the analyses show that a larger number of samples (or higher sampling rate) provides a better and more detailed analysis of the studied phenomenon, offering more information about the dynamic behaviour of the time series, and their interdependence. Using the B\&H hourly time series, specific diurnal, monthly and seasonal characteristics have been identified, such as the varying seasonal correlation of temperature and electricity consumption, which is very useful information for power system planners and operators. This feature can be 
observed with the linear regression approach as well, but without information on the time during the year in which this phenomenon occurs. It will be very interesting to use this approach for small consumer areas, which may gain further information about the behaviour of specific consumer groups. Today's technological advances in measuring and Automatic Measurement Reading (AMR) provide 15-minute information on consumption, and allow customer grouping in different categories. Analysis of small power system distribution areas and certain groups of consumers such as households, industry, etc., and the effect of air temperature variation on the consumption of these groups will be the subject of future research.

\section{Acknowledgement}

The authors would like to thank the institutions and colleagues who have made data used in this manuscript available.

\section{References}

[1] Henley, A., Peirson, J., Non-Linearities in electricity demand and temperature: Parametric Versus Non-Parametric Methods, Oxford Bulletin of Economics and Statistics 59: 149-162 (1997).

[2] Lee C.C., Chiu Y.B., Electricity demand elasticities and temperature: Evidence from panel smooth transition regression with instrumental variable approach. Energy Economics 33: 896-902 (2011).

[3] Parkpoom S., Harrison G.P., Bialek J.W., Climate change impacts on electricity demand, Proc. of the 39th UPEC: 1342-1346 (2004).

[4] Kervinen, T., Estimation of the temperature dependency of the Finnish electricity consumption. Helsinki University of Technology - Independent Research Project in Applied Mathematics (2008). www.sal.tkk.fi/publications/pdf-files/eker08.pdf.

[5] Valor E., Meneu V., Caselles V., Daily air temperature and electricity load in Spain. Journal of Applied Meteorology 40: 1413-1421 (2001).

[6] Pilli-Sihvola K., Aatola P., Ollikainen M., Tuomenvirta H., Climate change and electricity consumption-witnessing increasing or decreasing use and costs? Energy Policy 38: 2409-2419 (2010).

[7] Gupta E., Climate change and the demand for electricity: A non-linear time varying approach. Indian Statistical Institute-Delhi (2011). www.isid.ac.in/ pu/.../dec.../EshitaGupta.pdf.

[8] Stojanovic M.B., Bozic M.M., Stankovic M.M., Mid-term load forecasting using recursive time series prediction strategy with support vector machines. Facta Univ. Ser. Elec. Energ. 23: 287-298 (2010).

[9] Mamlook R., Badran O., Abdulhadi E., A fuzzy inference model for short-term load forecasting, Energy Policy 37: 1239-1248 (2009).

[10] Maia, C.A., Goncalves M.M., A methodology for short-term electric load forecasting based on specialized recursive digital filters, Computers \& Industrial Engineering 57: 724-731 (2009).

[11] Avdakovic S., Nuhanovic A., Kusljugic M., Music M., Wavelet transform applications in power system dynamics, Electric Power Systems Research 83: 237-245 (2012).

[12] Senjyu T., Tamaki Y., Takara H., Uezato K., Next day load curve forecasting using wavelet analysis with neural network. Electric Power Components and Systems 30: 1167-1178 (2002).

[13] Khoa T.Q.D., Phuong L.M., Binh P.T.T., Lien N.T.H., Application of wavelet and neural network to long-term load forecasting. Proc. of the Int. Conf. on Power System Technology-POWERCON: 840844 (2004).

[14] Zhang Q., Liu T., Research on mid-long term load forecasting base on wavelet neural network. Proc. of the Second Int. Conf. on Computer Engineering and Applications (ICCEA): 217-220 (2010).

[15] Antoniadis A., Brossat X., Cugliari J., Poggi J.M., Clustering functional data using wavelets. Society 43: 1-30 (2011). 
[16] Frunt J., Kling W.L., Ribeiro P.F., Wavelet decomposition for power balancing analysis. IEEE Trans. on Power Delivery 26: 1608-1614 (2011)

[17] Fung W.Y., Lam K.S., Hung W.T., Pang S.W., Lee Y.L., Impact of urban temperature on energy consumption of Hong Kong, Energy 31: 2623-2637 (2006).

[18] Moghaddas-Tafreshi S.M., Mahdi F., A linear regression-based study for temperature sensitivity analysis of Iran electrical load. IEEE Inter Conf on Industrial Technology 1-7 (2008).

[19] Avdakovic S., Nuhanovic A., Kusljugic M., Becirovic E., Turkovic E., Wavelet multiscale analyses of a power system load variance. Turkish Journal of Electrical Eng \& Comp Sci, DOI: 10.3906/elk1109-47 (2012).

[20] Avdakovic S., Ademovic A., Nuhanovic A., Insight into the Properties of the UK Power Consumption Using a Linear Regression and Wavelet Transform Approach. Elektrotehniški Vestnik/Electrotechnical Review 79: 278-283 (2012).

[21] Torrence C., Compo GP., A practical guide to wavelet analysis, Bulletin of the American Meteorological Society 79: 61-78 (1998).

[22] Grinsted A., Moore J.C., Jevrejeva S., Application of the cross wavelet transform and wavelet coherence to geophysical time series. Nonlinear Processes in Geophysics 11: 561-566 (2004).

[23] Holman I.P., Rivas-Casado M., Bloomfield J.P., Gurdak J.J., Identifying non-stationary groundwater level response to North Atlantic ocean-atmosphere teleconnection patterns using wavelet coherence, Hydrogeology Journal 19: 1269-1278 (2011).

[24] Furon A.C., Wagner-Riddle C., Ryan Smith C., Warland J.S., Wavelet analysis of wintertime and spring thaw $\mathrm{CO} 2$ and $\mathrm{N} 2 \mathrm{O}$ fluxes from agricultural fields. Agricultural and forest meteorology 148: 1305-1317 (2008).

[25] Keener V.W., Feyereisen G.W., Lall U. et al. El-Niño/Southern Oscillation (ENSO) influences on monthly NO3 load and concentration, stream flow and precipitation in the Little River Watershed, Tifton, Georgia (GA), Journal of Hydrology 381: 352-363 (2010).

[26] Terradellas E., Morales G., Cuxart J., Yague C., Wavelet methods: application to the study of the stable atmospheric boundary layer under non-stationary conditions. Dynamics of Atmospheres and Oceans 34: 225-244 (2001).

[27] Aguiar-Conraria L., Azevedo N., Soares M.J., Using wavelets to decompose the time-frequency effects of monetary policy. Physica A, 387: 2863-2878 (2008).

[28] Sen A.K., Zheng J., Huang Z., Dynamics of cycle-to-cycle variations in a natural gas direct-injection spark-ignition engine. Applied Energy 88: 2324-2334 (2011).

[29] Vacha L., Barunik J., Co-movement of energy commodities revisited: Evidence from wavelet coherence analysis. Energy Economics 34: 241-247 (2012).

[30] http://www.pol.ac.uk/home/research/waveletcoherence/

[31] http://www.nationalgrid.com/

[32] Parker D.E., Legg T.P., Folland C.K., A new daily Central England Temperature Series. 1772-1991, Int. J. Clim. 12 : 317-342 (1992). Available: www.metoffice.gov.uk/hadobs

[33] http://neuron.tuke.sk/competition/index.php 